\title{
The Situation of New Religious Studies in Vietnam
}

\author{
Truong Van Chung* and Nguyen Thoai Linh**
}

\begin{abstract}
There is a prominent phenomenon in the religious life of Vietnam, which is the emergence of "new religions". These phenomena have not only made the religious space of the nation more complex and multi-dimensional but also challenged stability and sustainable development within the religious communities in this key economic region. Having studied the new religious phenomenon in recent years, we have noted its progress and widespread characteristics within the ethnic communities. While it may appear that "new religion" is a simple and gentle concept and practice, it is in fact, intrinsically related to and has significant implications on the social life of the community members. However, there is a growing concern, considerable suspicion and anxiety with regards to its impacts on individuals, families, social and cultural traditions, beliefs and religions; many have opined that it
\end{abstract}

* Project Manager: The phenomenon of new religions in HCMC and the problems faced by the religious policy in Vietnam; truongchung@hcmussh.edu.vn

**Project Secretary: The phenomenon of new religions in HCMC and the problems faced by the religious policy in Vietnam; mai.linh99@yahoo.com 
is radically changing the peaceful cohabitation of diverse religious traditions, revealing a potential for conflicts across groups. Based on the religious reality of the Southern region of Vietnam, the Center for Religion Studies has implemented a project regarding new religions in Ho Chi Minh City (HCMC) and the problems faced by the religious policy in Vietnam. This article is an overview of the results of this project. ${ }^{1}$

Keywords: Phenomenon of new religions; New religious movement; Religious reconfiguration; Supreme Master Ching Hai; Yguan Dao; Cao Dai; Hoa Hao Buddhism

\section{Introduction}

Vietnam is a country of many ethnicities and multiple religions. Several religions have existed for a long time and cohabitated with Vietnam's ethnic groups such as Buddhism, Taoism, Catholicism, Protestantism, Cao Dai, Hoa Hao. These religions intermingle with Vietnamese traditional culture and become part of the cultural institutions in Vietnam today. There are also mainstream religions practiced by some ethnic minority communities such as Brahmanism in Champa, Theravada Khmer communities in the South Vietnam and Hindu communities from India, Malaysia and Vietnamese people of Indian origin, living in Ho Chi Minh City, Binh Duong and certain western provinces in southern Vietnam. New religions are a new theoretical and practical issue in Vietnam. Around the world this issue has been studied for many years, with many published works. However, direct research on this issue in Vietnam is still modest, with few scholars and researchers turning their attention to it. In this article, we provide an overview of the current state of the study of new religions in Vietnam as pioneered by domestic researchers.

${ }^{1}$ The Center for Religious Studies, VNU - HCM 


\section{The typical studies}

Various studies have been conducted to explore the phenomenon of "new religions". Professor Dang Nghiem Van, who is the author of many works on religious theory and practices in Vietnam, laid the basis for the Religious Studies of Vietnam. The author is credited for his analysis of "new religions", classification of the new religious phenomena on the basis of their generic features, identifying the sources for its spread and propagation. He proposed that new religions be studied systematically which would eventually help the respective state authorities adopt an informed perspective and help in efficient management.

In the article, Religious Processes through Human History (Van, 1999) and the book, Theory of Religion and Religion in Vietnam, he gave a general overview of religious movements in history. The author outlined five religious morphologies corresponding to five historical periods associated with major changes in religion. The morphology which corresponds to the "globalization trend" period is the religion that developed and adjusted itself to the drift of globalization evident in the post-industrial era. He reiterated that one of the critical issues of the given period would concern the issues affecting our understanding of alternative modes of religious practices. He also opined that the "new religions", a relatively new phenomenon started evolving in Vietnam during the time when the state was involved in the process of integrating with globalization. ${ }^{2}$

Within a historical framework, he argued that the religious movements are essentially dimensions of movements of humanity. He evaluated the new religions as floating and observed that majority of these religions tend to veer towards an extremist or counter-cultural perspective, albeit having counter examples where some of these newly evolving religions have been impactful when analysed according to their social and political dimensions. Van's work has been one of the first studies on new religions in Vietnam. It provided important information about the context of his research. In the article titled, New things appearing in religious life

2 Government religious Board Socialist Republic of Vietnam. (2006). Religion and religious policy in Vietnam, Hanoi. 
today, Van (1999), documented the long process of the evolution of these new religions and asserted that the major cause of the boom and the emergence of new religious phenomena in the society was "the transition from a mechanized society to an intellectual one with a global character" (Van, 1999).

Do Quang Hung, another noted scholar articulated the nature of these new religions, and raised methodological issues and principles for approaching new religious phenomena. Firstly, he considered this as important to clarify the conceptual boundaries of a few related terms and concepts such as communion, denomination, major religion, heresy, new religious names and so on. The author argued that through the analysis of the relationship between traditional beliefs and new religious phenomena one can perceive an important aspect of the transformation of beliefs, specifically, in the context of Vietnam. He observed that "all new religious phenomena seem to try to take advantage of the spiritual philosophy, rituals, and activity forms of the various indigenous beliefs to develop"(Hung, 2011).

The author classified new religions in Vietnam according to their specific characteristics and properties: religious forms completely new to Vietnam, forms related to Buddhism, sects closed to popular folk beliefs, extreme types of behavior, and unidentified types. He observed that the emergence of new religions "seem most unusual in the eyes of Vietnamese" 3 . He presented insights on theoretical and methodological concerns from his in-depth consultations and field research on the new religions in VinhPhuc: Church Longhuamaitreya and Jade Buddha - Ho Chi Minh Group.

He observed that pluralism in religion is an important aspect of new religions that seeks to alter religious systems and tends to threaten, both the cultural identity and the law of the land. However, he too, suggested that a more comprehensive analysis of the same is necessary which could potentially improve the "policies on religious renewal of the present day Vietnam Party and State."4

${ }^{3}$ Hung, D. Q. (2010). Religious studies: Characters and events. Ho Chi Minh City General Publisher.

4 The Institute of Religious Research. (2011). The Journal of Religious Studies, 03, p.5. 
His understanding of "religious reconfiguration", wherein he conceived religion as an intellectual resource is significant in our understanding of new religious phenomena. This conceptualisation helps in tracing the transition from traditional belief systems and doctrines to reconfigured beliefs and the doctrines of the new religions. The term "reconfiguration" reflects the constant change, movement, instability and uncertainty integral to new religions.

Mai Thanh Hai, an eminent scholar of new religions has contributed significantly and many of his articles, Doomsday and the phenomenon of extreme religions, The doctrines of farmers in the Mekong River Delta: From Buu Son KyHuong, Tu An Hieu Nghia to Lanh and Ong Nha Lon Doctrine and Baha'i Doctrine: its origin, the characteristics of its missionaries, and its introduction into Vietnam deserves mention. In pointing out extreme religions in the country such as Longhuamaitreya, Pha Toc, Supreme Master ChingHai, The Door of Heaven, the Holy Church, Falun Gon, to name a few, the author has outlined the relationship between the theory of doomsday and these extreme religions. He has argued that the cause of extreme religions and doomsday theory is the unintended implication and consequence of the development of modern science and technology and the growth of the industrial society that has caused environmental devastation, resource depletion, ozone thinning and perforation. In social terms, this includes crime, violence, increase in new diseases and the deterioration of traditional moral values etc. 5

Although the author has not clarified the characteristics of extreme religions, he has shown their social ramifications that includes panic, hopelessness, helplessness, and feelings of anxiety, insecurity and meaninglessness in the lives of the public. The author has warned that "exploring the extreme religions" should neither be confused with "spiritual activity" or with an understanding that "weird religions have no basis to arise and disturb the stability of human life"6. This advice is relevant for our research on "new religions" in Ho Chi Minh City.

5 Ibid., p.6.

${ }^{6}$ Hung, D. Q. (2010). The Research of religious characters and events, Ho Chi Minh City General Publisher. 
Regarding the religions of southern farmers (Hung, 2010), Hung describes and analyzes the characteristics, doctrine, and community activities of believers from Buu Son KyHuong, Tu An HieuNghia, Lanh and Ong Nha Lon and adds that they are religious to the extent that they have social organizations and parareligion. He further adds that religious sects consist of religious people that "sometimes carry a color of extremism and xenophobic nationalism in which many religions and sects have mixed superstition, multiple mysterious rituals and festivals, as well as sometimes used magic spells at a low level"7. Although the author did not use the term "new religion", he has indicated the characteristics of parareligions or the religions that seem to be "recycled traditional doctrines" which include multiple doctrines fused in them which have diverse beliefs and secularity, often referred to as "messianic religion". 8

Nguyen Hong Duong has written several articles related to the new religions in the journal Religious Studies and monographs. Most notable is the article, Some religions in Vietnam, in which he states that "the Party's views and policies of the State of Vietnam have a profound impact on the appearance of religion in Vietnam". ${ }^{9}$ The author has reviewed most of the major religions in Vietnam: Buddhism, Catholicism, Protestantism, Cao Dai, Tu An Hieu Nghia, Buu Son Ky Huong, Pure Land layperson (Tinh Do Cu Si), Buddhist Association, Baha'i , Nam Tong Minh Su Buddha Hall, Minh Ly religion, Tam Tong Mieu, and so on. Nguyen Hong Duong's contribution to the study of new religions deserves mention because of their theoretical and methodological impact.

Theoretically, placing new religious phenomenon in the overall history of the religious situation in Vietnam and using data and statistics from religious organizations and the Government Committee for Religions to study their progression have been of significant importance. Such a process has allowed him to demonstrate new religions as being part of the evolution of religious changes in Vietnam, map the entire range of evolution of

7 The Institute of Religious Research. (2000). The Religious Studies Review, 03, p. 63.

${ }^{8}$ Ibid., p. 64.

${ }^{9}$ Ibid., p. 67. 
religious thought in the given context, cite and examine the problems concerning the implementation of the policy about religious affairs.

His analysis has made other scholars probe into the nature and implications of a few local religions such as Buu Son KyHuong as a social precursor to the emergence and development of Tu An Hieu Nghia, Pure Land to name a few. ${ }^{10}$

The author additionally opines that the historical backdrop of the emergence of Ha Mon religion and the Duong Van Minh perhaps can be traced back to Christianity ${ }^{11}$. He further assesses the religions in terms of their complex nature, their social impact, concerns regarding the lack of knowledge of these new religions and an absence of policies and written sanctions that might have significant effects on the management of these religions. ${ }^{12}$

Nguyen Quoc Tuan suggested reviewing the term new religions and defended his use of the term in the following manner:

"The term of new religious phenomena that I use here is not meant to be distinguished from the traditional religions introduced into Vietnam since the beginning of AD to this century, and agricultural and indigenous religions. And this term, in the broadest sense, also refers to spiritual, mystical, pseudo-scientific phenomena which appear more and more, not only in a certain class of persons."13

Methodologically, he suggested that religion is supposed to be understood as "a holistic phenomenon of society, morale, and spirituality. Therefore, the study of religion is not just a few methods of several scientific disciplines to draw conclusions." He calls for a more involved, experiential perspective of studying religions. He asserts, that "the basis for study and religious policy making must be based on the reality of each people (nation), a

10 Ibid., p.67.

11 The Institute for Religion Research. (2010). Journal of Religious Studies, 07 (85), p.35.

12 Ibid., p.15.

13 The Institute for Religion Research. (2010). The Journal of Religious Studies, 08 (85). 
society or of each phenomenon becoming a movement or popular trends in society." 14

With reference to studies cited in the previous paragraph, echoing the scholars of new religions, one can say that Cao Dai and Hoa Hao, the indigenous religions in Vietnam emerging in the first half of the twentieth century could also be considered as new religions. New religions in Vietnam can be categorized in two phases: pre and post 1975. However one should be conscious of the possibility of new religions emerging in Vietnam ${ }^{15}$ before 1975 as its germination was very clearly noticeable even though the movements that typically correspond to these religions were not present ${ }^{16}$.

The article, Recognizing weird religions in our country in recent years, by Pham Van Phong and Nguyen Van Nhu ${ }^{17}$ offered a more political and legal orientation. Through statistics about the rapid development of strange religions in Vietnam, the authors considered strange religions as "spiritual medicines" to meet the needs of some people with vexing circumstances. However, they suggested that this form of expression of the strange religions in terms of religious belief is "very unusual" and stressed the negative manifestations of strange religions by adding that "almost all strange religions appearing in our country carry personal purposes, in order to gain illegal benefits in economic terms, take advantage of blind faith of the masses.... The negative image of the strange religions to social life is very deep, with some behaviors leading to death for those believing in strange religions". ${ }^{18}$

In his work on interrelationships between humans and religions, ethnic and tribal culture, problems faced by the people of these

14 Duong, N. H. (2013). Presentation on "New religious phenomenon derived from Christianity in our country today." International Scientific Seminar.

15 The Institute for Religion Research. (2011). The Journal of Religious Studies, 12 (102), p.10.

${ }^{16}$ Ibid., p.22.

17 The Institute for Religious Research. (2010). The Journal of Religious Studies, 12 (103) 2010, p.11.

18 The Institute for Religious Research. (2010). The Journal of Religious Studies, 01 (103). 
cultures, concerns with integration and development of these cultures, Prof. Ngo Van Le outlines a number of specific religious beliefs of the inhabitants of southern Vietnam. Although he does not directly mention the phenomenon of new religions, he contributes in building the methodological framework for studying religions in southern Vietnam. His anthropological understanding of religion relies on a principle of organic closeness between ethnicity and religion in the southern region.

Some of his suggestions about methodology place new religious phenomena in the larger picture of cultural space in South and Southeast Asia. He opines that "these religions had an impact on all aspects of Vietnamese life in the South. However, because the birth of these religions is based on the traditional culture of the Vietnamese people, which is the mixture of many religions, they are not sufficient to break the traditional cultural layer to establish a unique position in the spiritual life of the southern Vietnamese. Thus indigenous religions of the southern Vietnamese cannot spread to other communities". 19

The author provides a fairly accurate assessment in terms of geographic aspects of local religions in the South. He argues that "the natural conditions, social environment of new land are particularly important in the formation and development of indigenous religions." 20.These special natural and social conditions have led to many transformations of religions ${ }^{21}$. Mendicant (Khat $\mathrm{Si}$ ) and Pure Land Layman (Tinh Do $\mathrm{Cu} \mathrm{Si}$ ) to name a few.

Several other scholars have formulated their understanding of new religions (see Le, 2012 and others ) 22 and have examined the changes in both form and content of beliefs and religions. Although religious reform or distortion is separate from the topic of new

${ }^{19}$ Institute for Religious Research. (2008). The Journal of Religious Studies, 09 (63), p.44.

${ }^{20}$ Ibid., p.45.

${ }^{21}$ Le, N. V. (2012). Social Sciences and ethnic culture. Integration and Development, Ho Chi Minh City National University Publishing House.

22 The Institute for Religious Research. (2001). The Journal of Religious Studies, 01 (07), p.28. 
religions, they relate to each other and provide a general framework of the historical movement of religions and illuminate the beginning of the change of religious beliefs leading to the emergence of new or imported religions in Vietnam and Ho Chi Minh City.

About the new religions in Ho Chi Minh City, there are a few documents and research projects as well as plenty of articles about Supreme Master ChingHai ${ }^{23}$. Content from these web pages can be summarised in three points:

Some websites of government organizations, such as provincial electronic newspapers, law enforcement agencies and police express a clear view that Supreme Master Ching Hai (Thanh Hai Vo Thuong Su) is a heresy, which affects people and negatively impacts security and social order. Religious sites consider Supreme Master Ching Hai to be an untrue denomination that has distorted major religions. The sites of Supreme Master Ching Hai however, praise and offer lessons of Supreme Master Ching Hai on vegetarianism, environment, real meditation, and so on. While all of these websites refer to the new religions, almost all of them initially introduce themselves under and the purview of Buddhism or Catholicism.

Scientists researching new religions in the North call these new religions "strange religions". They have a significant amount of information about the operations of the strange religions in the northern delta such as: Longhuamaitreya, Jade Buddha - Ho Chi Minh, Supreme Master Ching Hai, Hoang Thien Long, Lac Hong Au Co, Uncle Ho, Hong Thien A Di Da, Trang Phuong Hy Di Lac religion, Duc Khai religion, and Falun Gong g. Researcher Truong Hai Cuong at the Center for Contemporary Religious Studies, Hanoi University of Social Sciences and Humanities, from his detailed study also has some information and reliable data from surveys, social surveys on a few strange religious activities in

23 Web pages such as Phapluattp.vn; Cand.com.vn; Baokhanhhoa.com.vn; baocantho.com.vn; Thuvienhoasen.org; Baobinhdinh.com.vn; Thegioivohinh.com;

Tructiepcauthongthuongde.org. Suprememastertv.com; 
Hanoi that includes the number of strange religions, the number of believers, strange religion's life, and other related social issues. ${ }^{24}$ Through the general report of a survey about strange religions in Hanoi, we find that new religious forms appear more vigorously and more actively in the Northern Delta. Although the studies, investigations and surveys are being carried out urgently and scientists have valuable data and information for the study of new religions, publications and academic exchanges on this subject remain modest.

Some representative scientific research on the culture and beliefs of religions in the South, Southeast and Ho Chi Minh City include the scientific research project of Prof. Ngo Van Le, The characteristics of beliefs, religions and cultural activities of the Southern communities (2010) which is a monograph with comprehensive research on religions and cultural activities of ethnic communities in the South. This project has clarified many issues on the situation and characteristics, religious activities and religious and traditional culture of ethnic groups in the South (Vietnamese, Khmer, Hoa, and Cham). In addition to the outline of the characteristics of beliefs, religions and culture of each ethnic group, the project also forecasts about the movement and changes of religious beliefs. This scientific study helps the team continue to inherit and study new religions based on the existing foundation of humanity and the kind of environment that the society provides in the southern region, as well as further clarify the impact and influence of these elements on new religions.

A massive and sophisticated scientific study of a group from the Department of Philosophy, HCM city-Vietnam National University of Social Sciences and Humanities investigating the problem of lifestyle and thinking of the community of Vietnamese in the South East in the process of innovation and current international integration (2011) clarified the situation, appearance, and characteristics of thinking inherent in the traditional lifestyle of the Vietnamese community in the Southeast region and offered suggestions and solutions to develop the thinking. A major

24 The Institute for Religious Research.(2008).The Journal of Religious Studies, 04 (58), 43. 
contribution of this project was to clarify the cultural and spiritual life of the Southeast, which obviously was also a factor impacting the cultural and spiritual life of the community of new religious believers. A scientific study: "Ho Chi Minh City cultural address," with four episodes written by Prof. Tran Van Giau and researcher Tran Bach Dang described not only place, characters and events but also gave a comprehensive outline of the appearance and characteristics of thoughts and beliefs in Ho Chi Minh City (1998). A scientific research at municipal level: The urgent problems of religious life in Ho Chi Minh City in recent years edited by Prof. Do Quang Hung, is also a monograph on religious life in Ho Chi Minh City with reliable statistics from trusted sources and fieldwork, interviews of participants and results of sociological survey data. This provided a panoramic image of religious life in Ho Chi Minh City and raised issues for both religious organizations and the State management of religion and religious work. The topic was commissioned in 2009 but the urgency of issues that arose regarding the religious life in Ho Chi Minh City and the realistic aspects of religious life specifically, remain valuable.

In order to have a deep and broad foundational understanding of culture and religion in Vietnam, a few previous works deserves mention (Appendix 1). The research team is particularly focused on these local religions as some Western scholars considered these religions to be the new religious form. ${ }^{25}$ On the other hand, in the light of history, these local religions have a certain relevance to the new religions derived from indigenous beliefs and religions in Vietnam and specifically Ho Chi Minh City today. New religions in Ho Chi Minh City seem like a group of trees growing on the fertile ground of southern culture, creeds and religions. Thus, when studying them, we must have extensive background knowledge. The team acknowledges the same and therefore, has referred to most of the meticulous and credible work on this topic by established scholars (For a full list of references see Appendix 2). In addition to these, there

${ }^{25}$ Cuong, T.H. (2012). Results of survey analyst, the problem of strange religion in local Hanoi - problems and solution, undertaken by the Department of Science and Technology in Hanoi. 
are many research materials from dissertations, theses, websites on the subject of culture, creeds, religions in the South with the data and annual reports of Ho Chi Minh City departments (The Committee for Religious, Affairs Department, the Department of Culture - Information Tourism, etc.) that were consulted and we do propose future scholars to take note of these alternative sources for acquiring a more detailed and contemporary perspective on the situation of new religions in Vietnam.

\section{Discussion}

We conclude the article with a few observations regarding new religions in Vietnam. This is an objective phenomenon in human life. In many, not all work that has explored the dimension of new religions we often encounter gaps in our understanding and awareness of a specific phenomenon, encounter multiple views and different opinions about the name, origin, nature, characteristics and types of new religions. So far, the idea of what constitutes a new religion is still fuzzy, because they are so diverse in form and uncertain in nature. However, the activities and spread of new religious communities in the provinces and cities in Vietnam is an ongoing process. The new religions have posed many problems in terms of awareness and attitudes towards religious affairs. The issues challenge theory and practice, raising questions such as "Are the new religions good or evil?", "Are they existing with each other positively or opposing and conflicting with contemporary society?" There are questions on the extent of their influence, the reactions of society and on how best to implement the right policies and laws on these religions by the Party and State of Vietnam. The problem is not just concerns or suspicions of society but also the imperative of the present life that requires scholars in the field of social and humanities to further study both the theory and practice of the new religions.

From the results of research projects and regarding research on the new religion in Vietnam, we believe that: "Religion is a new organizational form ...........They reflect the large fluctuations of cultural life, the spirit of contemporary society and the need for 
spiritual transformation of a group of people in the cultural environment.....specific society" ${ }^{26}$.

There are many contributions to the continuous study of new religions, which are guidelines for research methods, approach principles, ideas, comments and suggestions about the appearance, characteristics and classification of new religions. They are practical and valuable contributions to the research of the team.

The research classifies new religions in Vietnam as follows: New religions of indigenous origins; New religions from the religious syncretic; New religions derived from Christianity, Buddhism, Hinduism.

Initially, we studied some specific new religions in Vietnam. However, it was later found that the study of new religions in Vietnam, in general, and Ho Chi Minh City, in particular, should be pursued to analyse deeply and more systematically both theoretical and practical issues, such as:

Further clarification of the definition and characteristics of the new religions is required. Clarification regarding some specific new religions which exist in Vietnam is important for any such studies (For example, Jehovah's Witnesses, Mormons; Falun Gong; I Guan Tao, Krishna Bhakti; Sai Baba). The factors of society, cognition and psychology in relation to the transformation of beliefs towards new religions are to be studied in depth. The social role of new religions, general assessments and forecasts become important for any analyses. Currently, most researchers represent their views through short articles, so in-depth, detailed, monograph-length studies are still lacking. Nguyen Quoc Tuan opines that “...there are not really long-term studies and more detailed works as well as serious assessments about this phenomenon from the researchers and authorities. The system of theory and new research methods is still in the initial step." 27

26 The Institute for Religious Research, the Journal of Religious Studies, No. 02/2009 - Tran Tien Thanh

27 Murray Rubinstein, 2004, New religious Movements in Viet Nam, Indonesia and Philippines, University of Oxford. USA. 
Currently, the researchers are carrying out scholarly work on the basis of these studies and hope to obtain deeper and more valuable research on new religions to capture the changes in indigenous religious life.

\section{Appendix 1}

Relevant works to $\mathrm{b}$ consulted for a more synthesized view on the emergence of and evolution of religions: Work by Hung, 1953; Hau, 1956; Kim, 1966; Buu Son KyHuong (Vuong Kim, 1966); a monographic work of history: Tu An HieuNghia religion of Southern Vietnamese (1867-1975) of Dinh Van Hanh, 1996; Documents HoaHao Buddhist doctrine (1964); Lessons of HoaHao Buddhist doctrine (1976) compiled and preached Duc Huynh Giao; a monograph of Nguyen Van Hau on the recognition of HoaHao Buddhists in 1974; reports on the organization and operation of HoaHao forces and religious activities in the Center for National storage II; History of Cao Dai hidden period (1920-1926) (Le Anh Dung, ThuanHoa Publishing House, 1996); Cao Dai religion and politics (Pham KyChuong - thesis, National Academy of Saigon Public Administration in 1937 to 1954?); post-graduate thesis "Political status of Cao Dai" by Tran Van Rang, Saigon University of Arts, 1975; Looking back on 50 years of history of Cao Dai of Nguyen Thanh Long (1926-1975), 1975; The Initial study of Cao Dai (Dang Nghiem Van ed, 1995); articles about "Ngu chi Minh Dao" in the South important for understanding the history of Vietnam and NhatQuan religion as: Southern land-cultural premise of Cao Dai (Hue Kha, Religion Publisher, Hanoi, 2008); Southern land-legal premise for Cao Dai (Hue Kha, Religion Publishing House, Hanoi, 2008) and Some aspects of Phat Duong Nam Tong, Minh Su Dao ${ }^{28}$ by Tran Tien Thanh.

28 The authors, 2008, The Transformation of Religious beliefs in Vietnam today, Publishing World House Hanoi. 


\section{Appendix 2:}

History of exploring the Southern region (Huynh Lua, ed, HCM City Publisher, 1987), The history of Southern reclamation (Son Nam, Art Publishing House, Vietnam, 1994); Saigon Culture (Vietnam, 2000); The Culture of Saigon - Ho Chi Minh City in the twentieth century, The Folklore of southern Vietnamese (Thach Phuong, Ho Le, Huynh Lua, Nguyen QuangVinh, Social Science Publisher, Hanoi, 1998); The problem of ethnology and religions in the South (Phan An editor, HCM City publisher, 1994); Southeastern - People and Culture (PhanXuan Bien, HCM City VNU publisher -, 2004); TheSouthern culture in the social space of Southeast Asia (The Centre for Vietnam Southeast Asia Research, VNU publisher. 2000); Saigon - Ho Chi Minh City in twentieth century (Nguyen The Nghia - Le Hong Liem editor, HCM City Youth Publishing House); Urbanization and poverty reduction issues in the city - theory and practices (Nguyen The Nghia, Mac Duong, Nguyen QuangVinh (eds), Social Sciences Publishing House, Hanoi, 2005); The Southern Social Sciences (Bui The Cuong editor, Encyclopedia Publishing House, Hanoi, 2009) and Saigon - GiaDinh - Ho Chi Minh City - 40 year executing Uncle Ho's testament (The General Publisher, Vietnam, 2010). 